\title{
High glucose promotes the aging of human dental pulp cells through Wnt/beta-catenin signaling
}

\author{
Mona Asghari ${ }^{1, B-D}$, Nikoo Nasoohi ${ }^{1},{ }^{,}$, , Mahshid Hodjat ${ }^{2, A, C, E, F}$ \\ ${ }^{1}$ Department of Biochemistry and Biophysics, Faculty of Advanced Science and Technology, Tehran Medical Sciences, Islamic Azad University, Tehran, Iran \\ ${ }^{2}$ Dental Research Center, Dentistry Research Institute, Tehran University of Medical Sciences, Iran \\ A - research concept and design; $\mathrm{B}$ - collection and/or assembly of data; $\mathrm{C}$ - data analysis and interpretation; \\ $D$ - writing the article; $E$ - critical revision of the article; $F$ - final approval of the article
}

Address for correspondence

Mahshid Hodjat

email:mhodjat@tums.ac.ir

Funding sources

None declared

Conflict of interest

None declared

Acknowledgements

This work was supported by Tehran University of Medical Sciences (TUMS) (grant No. 96-03-70-36871) and Islamic Azad University in Iran.

Received on June 26, 2020

Reviewed on August 19, 2020

Accepted on November 4, 2020

Published online on March 31, 2021

Cite as

Asghari M, Nasoohi N, Hodjat M. High glucose promotes the aging of human dental pulp cells through Wnt/beta-catenin signaling. Dent Med Probl. 2021;58(1):39-46.

doi:10.17219/dmp/130090

DOI

$10.17219 / \mathrm{dmp} / 130090$

Copyright

○) 2021 by Wroclaw Medical University

This is an article distributed under the terms of the

Creative Commons Attribution 3.0 Unported License (CC BY 3.0)

(https://creativecommons.org/licenses/by/3.0/).

\begin{abstract}
Background. Diabetes is one of the most common metabolic diseases that disrupt the functioning of different body organs, including oral tissue. Some diabetic complications remain even after the control of the hyperglycemic condition. The adverse effect of hyperglycemia on the pulp structure and function has been shown previously.

Objectives. The purpose of this study was to investigate the effect of the hyperglycemic state on the aging of pulp cells and evaluate the role of Wnt signaling as the underlying mechanism of this process.

Material and methods. The isolated pulp cells were cultured in the Minimum Essential Medium (MEM)-alpha for 7, 14 and 21 days under the influence of glucose at concentrations of $5 \mathrm{mM}, 20 \mathrm{mM}$ and $30 \mathrm{mM}$. The 3-(4,5-dimethylthiazol-2-yl)-2,5-diphenyltetrazolium bromide (MTT) assay was used to evaluate cell viability, the beta-galactosidase test was applied to assess cellular senescence and gene expression was measured with quantitative real-time polymerase chain reaction (qRT-PCR).

Results. The results of this study showed that cell proliferation decreased following exposure to 20 and $30 \mathrm{mM}$ glucose, which was accompanied by an increased number of senescent cells and an increased p21 expression. There was a significant increase in beta-catenin and Wnt1 expression in response to high glucose. Treatment with beta-catenin inducer enhanced cellular aging in the hyperglycemic state, while betacatenin inhibitor decreased the senescence response.

Conclusions. The present study further confirmed the effect of the high-glucose condition on pulp cell aging and suggests a role for beta-catenin in the induction of cellular aging. Targeting the key regulators of cellular aging in pulp tissue might lead to the development of new therapies for the prevention and treatment of endodontic complications in diabetic patients.
\end{abstract}

Key words: Wnt signaling, beta-catenin, pulp stem cells, diabetes, senescence 


\section{Introduction}

Diabetes is among the most common metabolic diseases in the world, being responsible for millions of deaths per year. Diabetes is not only recognized as a disease, but also as a series of diseases that may affect the body's systems and many organs. The global prevalence of diabetes in 2010 was $8.3 \%$, representing 387 million patients; the number is estimated to reach 552 million by $2030 .^{1,2}$ Impaired insulin secretion and function are typical features of the diabetic state, which is characterized by high blood glucose. Diabetes-induced changes in the metabolism of carbohydrates and lipids cause extensive modifications in the function and structure of the vascular and nervous systems, which consequently affect various organs, such as the heart, kidney, eyes, etc.

A large number of studies have shown the influence of high glucose on oral tissue. ${ }^{3,4}$ People with diabetes are at higher risk of periodontal disease than healthy people. Indeed, diabetes has been identified as a major risk factor for periodontitis and gingivitis. ${ }^{5}$ Other oral manifestations and complications of diabetes include salivary dysfunction, taste disturbance, increased prevalence of oral mucosa lesions, and poor wound healing capacity. ${ }^{4}$ There are also profound changes in the alveolar bone function, accompanied by reduced osteogenic capacity and bone remodeling, which could lead to tooth loss. Studies on the adverse effects of diabetes on pulp tissue are limited. Based on histopathological observations, diabetic pulp undergoes significant changes, including increasing the basement membrane thickness, decreasing the lumen diameter and obliterative endarteritis, contributing to poor vasculature and a higher risk of pulp necrosis. ${ }^{6}$ Also, calcifications in diabetic pulp are frequently observed, resembling age-associated changes in old individuals. ${ }^{7}$ At the cellular level, hyperglycemia may enhance the expression of inflammatory factors and structural proteins, such as collagen and osteopontin, ${ }^{8,9}$ which is accompanied by an increase in the expression of oxidative stress-related enzymes. ${ }^{10}$ Mesenchymal stem cells (MSCs) residing in human pulp exhibit a high capacity of proliferation and odontoblastic differentiation, which was found to be reduced in diabetic rats, thus affecting the regeneration of dentin and the formation of the dentin bridge. ${ }^{11}$ Still, the underlying mechanism of hyperglycemia-induced cellular and molecular changes in pulp tissue has not been fully elucidated. There is evidence showing the causative effect of hyperglycemia in the induction of cellular aging in different cell types as well as diabetic models. ${ }^{12-14}$

Understating the detailed molecular mechanism of diabetic-induced changes in the cell function and targeting the key regulatory factors can be of great importance in the development of new therapeutic approaches in endodontic treatment for patients suffering from diabetes. In the present study, the effect of high glucose on the induction of the senescence response in cultured pulp cells was investigated. Also, the potential role of Wnt signaling in high glucose-induced senescence was evaluated.

\section{Material and methods}

\section{Material}

Glucose was purchased from Merck (CAS 77938-63-7; Darmstadt, Germany). The inhibitor of Wnt/beta-catenin pathway PNU-74654 (CAS 113906-27-7) was from Santa Cruz Biotechnology (Santa Cruz, USA), and both 3-(4,5-dimethylthiazol-2-yl)-2,5-diphenyltetrazolium bromide (MTT) and 5-bromo-4-chloro-3-indolyl- $\beta$-Dgalactopyranoside (X-Gal) were from Roche Diagnostics (Mannheim, Germany). Lithium chloride (LiCl; CAS 7447-41-8), magnesium chloride $\left(\mathrm{MgCl}_{2}\right)$, potassium ferricyanide $\left(\mathrm{K}_{3}\left[\mathrm{Fe}(\mathrm{CN})_{6}\right]\right)$, potassium hexacyanoferrate (II) trihydrate $\left(\mathrm{K}_{4}\left[\mathrm{Fe}(\mathrm{CN})_{6} \cdot 3 \mathrm{H}_{2} \mathrm{O}\right]\right)$, and dimethyl sulfoxide (DMSO) were purchased from Merck. Fetal bovine serum (FBS) and phosphate-buffered saline (PBS) were from Biowest (Nuaillé, France). The sources of all other materials used in the experiments were indicated in the text.

\section{Primary cell culture, stem cell characterization and cell treatment}

Pulp cells were isolated from dental pulp tissue. For this aim, the teeth extracted from 3 healthy patients attending the Dental Policlinic of Tehran University of Medical Sciences in Iran were transferred immediately to the laboratory in Minimum Essential Medium (MEM)-alpha (Biowest) with $20 \mathrm{mM}$ 4-(2-hydroxyethyl)-1-piperazineethanesulfonic acid (HEPES) buffer, pH 7.4. Informed written consent was obtained from the subjects for conducting the study. The tissues were digested in the collagenase-dispase enzyme solution (Invitrogen, Waltham, USA) and the primary cells were isolated according to the previously reported method. ${ }^{15}$ The isolated cells were cultured in MEM-alpha supplemented with $10 \%$ FBS under the humidified condition at $37^{\circ} \mathrm{C}$ with $5 \% \mathrm{CO}_{2}$. The pulp cells were characterized by the expression of their surface cluster of differentiation (CD) markers and their potential to differentiate into different cell lineages according to the previously described techniques. ${ }^{16}$

To study the effect of glucose on pulp cells, a stock solution of $100 \mathrm{mg} / \mathrm{mL}$ glucose was prepared in MEM-alpha. The solution was filtered and the appropriate volume was added to each well containing the culture medium to give the total concentrations of $20 \mathrm{mM}$ and $30 \mathrm{mM}$ glucose. The pulp cells were treated with the medium containing $20 \mathrm{mM}$ or $30 \mathrm{mM}$ glucose for 7, 14 and 21 days. The control groups were treated with $5 \mathrm{mM}$ glucose. The medium was refreshed every 3 days. The cells were exposed to $\mathrm{LiCl}(6 \mathrm{mM})$ or PNU-74654 $(10 \mu \mathrm{M})$ on the same day of glucose treatment. 


\section{MTT assay}

The cells were seeded in 96-well tissue culture plates at a density of 4,000 cells/well. After overnight rest time, the cells were treated with different concentrations of glucose in MEM-alpha supplemented with FBS. Cell proliferation was measured with the MTT assay, which is based on the cleavage of the tetrazolium salt (MTT) by metabolically active cells to form the purple formazan crystal dye. After removing the cell culture medium from each well, $100 \mu \mathrm{L}$ of the MTT solution ( $50 \mathrm{mg} / 10 \mathrm{~mL}$ PBS) was added and the plate was incubated at $37^{\circ} \mathrm{C}$ for $3-4 \mathrm{~h}$. Following the formation of formazan crystals, the MTT solution was substituted with $50 \mu \mathrm{L}$ of DMSO to dissolve the crystals while shaking for $20 \mathrm{~min}$. The absorbance was measured at wavelengths of $570 \mathrm{~nm}$ and $650 \mathrm{~nm}$ by means of a multi-well spectrophotometer (BioTek Instruments, Inc., Winooski, USA).

\section{Beta-galactosidase assay}

Beta-galactosidase cytochemical staining was used to evaluate cellular senescence. The beta-galactosidase enzyme is expressed in the lysosomes of all cells at $\mathrm{pH}$ 4 , which is the optimum $\mathrm{pH}$ of the enzyme activity. The senescent cells with high beta-galactosidase activity are distinguished under high $\mathrm{pH}$ 6. For this experiment, the cultured cells in 24-well plates were washed with PBS and fixed with paraformaldehyde $2 \%$ in PBS for $5 \mathrm{~min}$, which was followed by washing with PBS twice. The senescence-associated (SA)-beta-galactosidase staining solution was prepared in PBS containing $\mathrm{MgCl}_{2}$ $(2 \mathrm{mM}), \mathrm{K}_{4}\left[\mathrm{Fe}(\mathrm{CN})_{6} \cdot 3 \mathrm{H}_{2} \mathrm{O}\right](2.12 \mathrm{mg} / \mathrm{mL}), \mathrm{K}_{3}\left[\mathrm{Fe}(\mathrm{CN})_{6}\right]$ $(1.64 \mathrm{mg} / \mathrm{mL})$, and $\mathrm{X}-\mathrm{Gal}(1 \mathrm{mg} / \mathrm{mL})$ at $\mathrm{pH}$. The $500 \mu \mathrm{L}$ of the solution was added to each well and the plate was incubated at $37^{\circ} \mathrm{C}$. After $24 \mathrm{~h}$, the staining solution was removed and the cells were rinsed twice in PBS. Finally, $500 \mu \mathrm{L}$ of the $\mathrm{SYBR}^{\circledR}$ green solution $(1: 10,000)$ (Sigma-Aldrich, St. Louis, USA) was added to each well. The blue X-Gal-stained cells were counted under light microscopy (Leica Camera, Wetzlar, Germany). The number of blue cells was recorded in at least 10 different microscopic fields and the percentages were calculated from the total number of fluorescent nuclei that were detected in the same field under fluorescence microscopy. ${ }^{17}$

\section{Real-time polymerase chain reaction and gene expression assessment}

Total RNA was extracted from the control and treated samples with the use of TRI Reagent ${ }^{\circledR}$ (Sigma-Aldrich), with standard procedures based on phenol-chloroform extraction and ethanol precipitation. The extracted RNA was quality-controlled for purity and integrity with agarose gel electrophoresis and the measurement of the
$260 / 280 \mathrm{~nm}$ ratio of absorbance. Next, $1 \mu \mathrm{g}$ of RNA was treated with $0.1 \mathrm{U}$ of RNase-free DNase I (Roche Applied Science, Mannheim, Germany) and converted to cDNA, using BioFact ${ }^{\mathrm{TM}}$ RT-Kit (BIOFACT, Daejeon, South Korea) according to the manufacturer's protocol. Subsequently, $2 \mu \mathrm{L}$ of cDNA was used as a template for quantitative real-time polymerase chain reaction (qRT-PCR) with $1 \mu \mathrm{L}$ of primers, $10 \mu \mathrm{L}$ of BioFact ${ }^{\mathrm{TM}}$ 2X Real-Time PCR Master Mix and $1 \mu \mathrm{L}$ of random hexamer, and $6 \mu \mathrm{L}$ of sterile, diethyl pyrocarbonate (DEPC)-treated water. The conditions for qRT-PCR include: $15 \mathrm{~min}$ at $95^{\circ} \mathrm{C}$ for denaturation; $20 \mathrm{~s}$ at $95^{\circ} \mathrm{C}$; $20 \mathrm{~s}$ at $60^{\circ} \mathrm{C}$; and $30 \mathrm{~s}$ at $72^{\circ} \mathrm{C}$.

The sequence of primers was as follows: p21 F 5'-GGCACCCTAGTTCTACCTCA-3', R 5'-CTCCTTGTTCCGCTGCTAAT-3'; Wnt-1 F 5'-GTTCCATCGAATCCTGCACG-3', R 5'-CTGCCTCGTTGTTGTGAAGG-3'; beta-cat F 5'-TCCCTGAACTGACAAAACTGCT-3', R 5'-CACCATCTGAGGAGAACGCAT-3'; and GAPDH F 5'-CACATGGCCTCCAAGGAGTAA-3', R 5'-TGAGGGTCTCTCTCTTCCTCTTG-3'.

The PCR products were visualized on $1 \%$ agarose gel and melting curves were evaluated for single peaks. The relative fold change was calculated relative to the control group after normalization to the internal control gene, glyceraldehyde 3-phosphate dehydrogenase (GAPDH). The formula $2^{-\Delta \Delta \mathrm{C}^{t}}$ was applied as the standard method for determining gene expression changes.

\section{Statistical analysis}

The significance of the obtained data was determined using two-way analysis of variance (ANOVA) followed by Tukey's multiple comparison test with the help of the IBM SPSS Statistics for Windows software, v. 20.0 (IBM Corp., Armonk, USA). All the experiments were performed at least twice, each in triplicate on separate dates. The level of significance was set at 0.05 .

\section{Results}

\section{Characterization of pulp mesenchymal stem cells}

The extracted pulp MSCs successfully adhered to the plastic cell culture plates and were positive for MSC surface markers CD73, CD90 and CD105, as assessed by flow cytometry and the immunofluorescence analysis (Fig. 1A,1B). Also, the cells showed the lack of the expression of hematopoietic markers CD 45 and CD 34. The MSCs could differentiate into different cell types, including the osteogenic, adipogenic and chondrogenic lineages (Fig. 1C). 


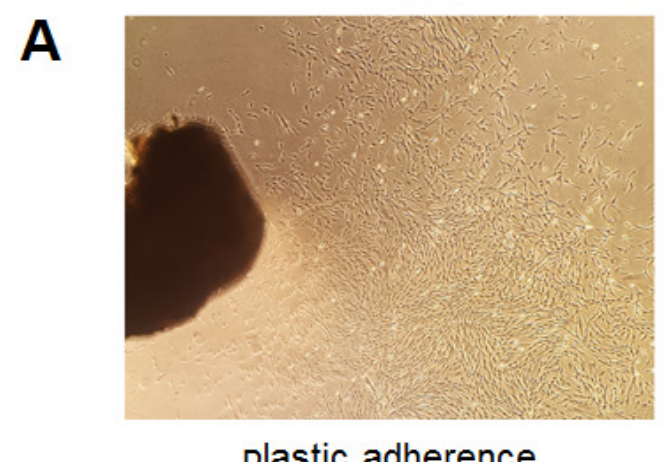

plastic adherence

B
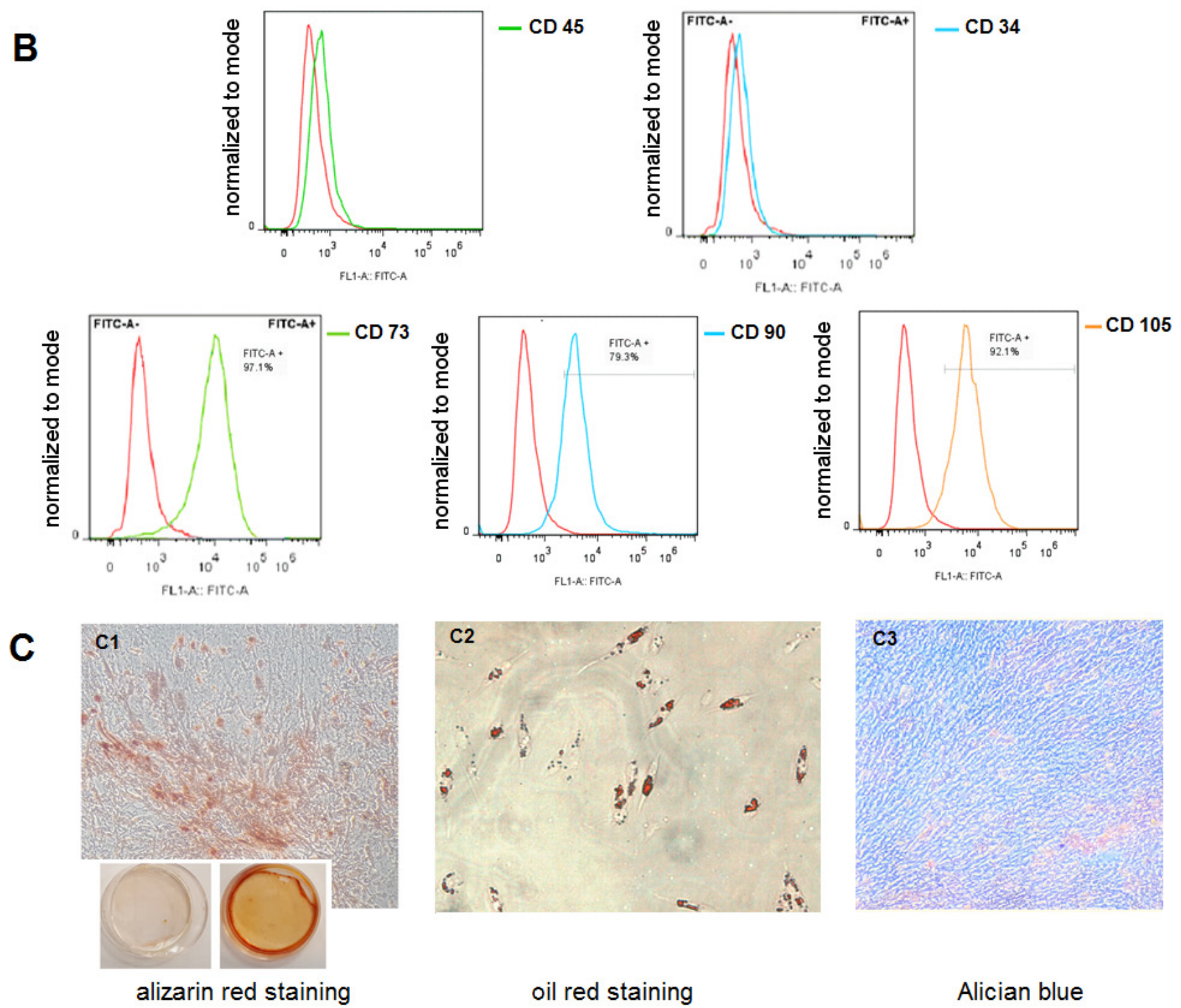

Alician blue

Fig. 1. Characterization of pulp mesenchymal stem cells (MSCs)

A - plastic adherence; B - MSC surface markers; C - differentiation of MSCs into osteoblasts (alizarin red staining), adipocytes (oil red staining) and chondrocytes (Alician blue staining).

\section{High glucose reduced the proliferation of pulp cells}

The proliferation rate of the isolated pulp cells was examined at a high concentration of glucose during long-term exposure by means of the MTT assay. The results showed that while the number of cells in the control group ( $5 \mathrm{mM}$ glucose) increased continuously, exposure to $20 \mathrm{mM}$ and $30 \mathrm{mM}$ glucose significantly inhibited cells proliferation on days 14 and 21 (Fig. 2A). 
A

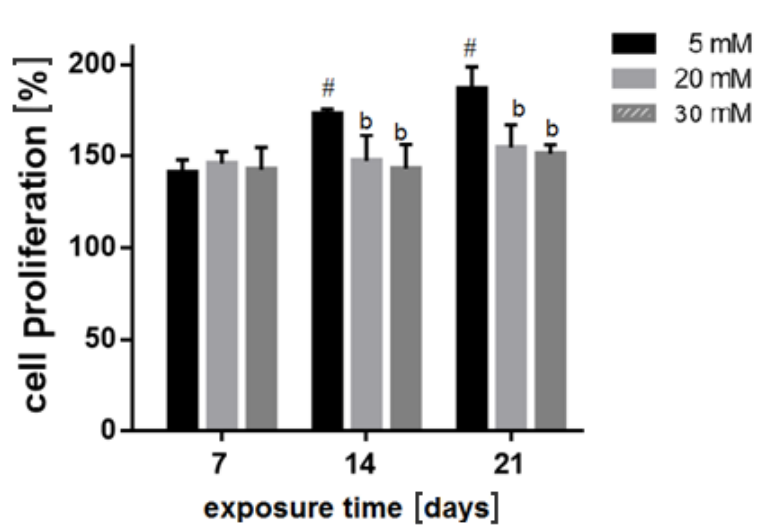

B

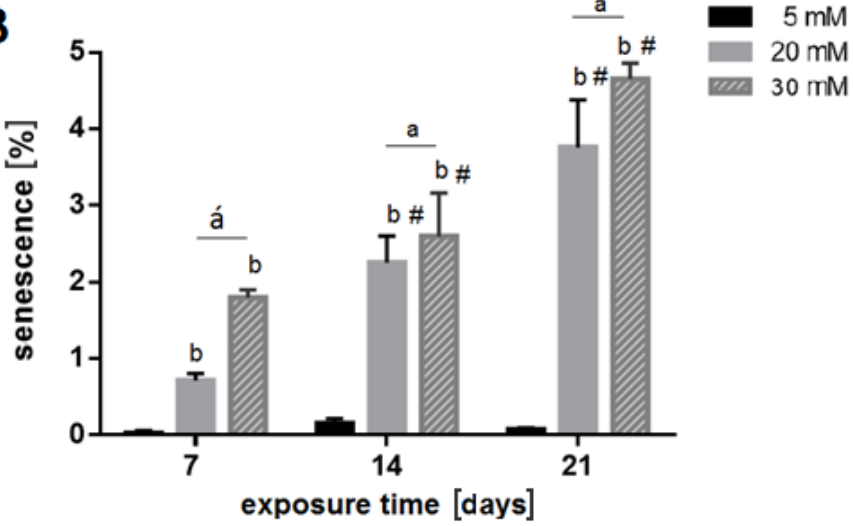

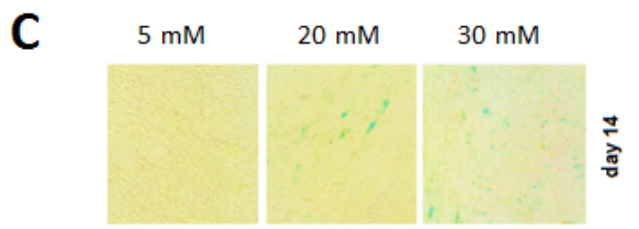

Fig. 2. Cell proliferation at different concentrations of glucose on days 7, 14 and 21 (A), the corresponding diagram of the percentage of the senescent cells increased at high glucose concentrations (B) and senescence-associated (SA) beta-galactosidase staining (the senescent cells with beta-galactosidase activity with blue color developed in their cytoplasm) (C)

a significantly different from group $20 \mathrm{mM}$ on a specific day $(p<0.05){ }^{\text {a }}$ significantly different from group $20 \mathrm{mM}$ on a specific day ( $\left.p<0.001\right)$;

b significantly different from control on a specific day $(p<0.001)$; \# significantly different from control on day $7(p<0.001)$.

For $A$ and $B$, data presented as mean $(M) \pm$ standard deviation (SD).

\section{High glucose induced cellular senescence in pulp cells}

To evaluate the presence of the senescent cells among the pulp cells treated with glucose, the beta-galactosidase assay was performed. The results showed that exposure to high concentrations of glucose increased SA beta-galactosidase activity in a dose-dependent manner (Fig. 2B,2C). The number of aging cells increased with the passing time and an increasing glucose concentration. To further confirm the senescence response, the expression of the p21 marker associated with cell cycle arrest was assessed. High glucose resulted in an enhanced expression of p21 after 7-, 14-, and 21-day exposure (Fig. 3).

\section{Increased beta-catenin and Wnt 1 expression at high glucose}

There was a significant increase in the expression of beta-catenin at $30 \mathrm{mM}$ glucose as compared to control $5 \mathrm{mM}$ glucose on day $7(p<0.001)$. Exposure to $20 \mathrm{mM}$ and $30 \mathrm{mM}$ glucose enhanced Wnt1 expression in the cultured pulp cells (Fig. 4).

\section{High glucose-induced senescence response is mediated by beta-catenin}

To evaluate the role of Wnt signaling in the glucoseinduced senescence response, the cells were treated with beta-catenin inhibitor - PNU-74654 - and betacatenin inducer - $\mathrm{LiCl}$. The results showed that $\mathrm{LiCl}$ aggravated cellular senescence in the presence of high concentrations of glucose $(20 \mathrm{mM}$ and $30 \mathrm{mM})$. Also, an increased percentage of senescent cells alleviated in the presence of PNU-74654 $(10 \mu \mathrm{M})$ at high glucose concentrations (Fig. 5A). Similarly, LiCl induced p21 expression, while exposure to PNU-74654 reduced the p21 level under hyperglycemic conditions, as measured by qRT-PCR (Fig. 5B).

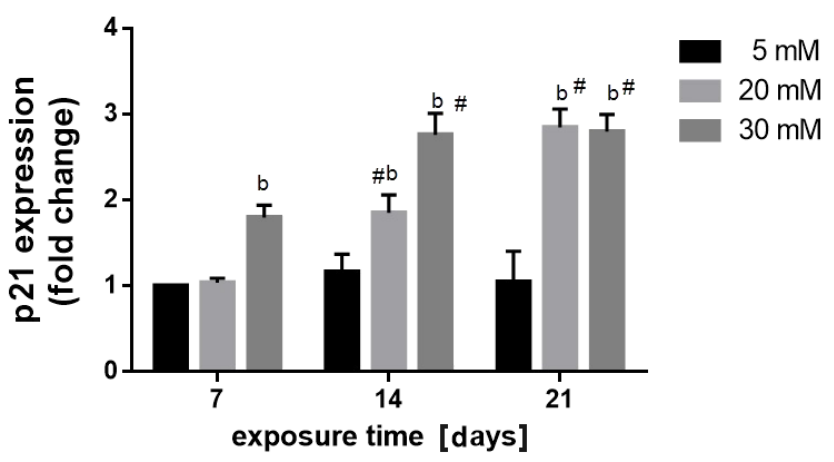

Fig. 3. Quantitative real-time polymerase chain reaction (qRT-PCR) analysis of gene expression of p21 in the cells exposed to different concentrations of glucose on days 7, 14 and 21

${ }^{\mathrm{b}}$ significantly different from control on a specific day $(p<0.001)$;

\# significantly different from control on day $7(p<0.001)$.

Data presented as $M \pm S D$. 

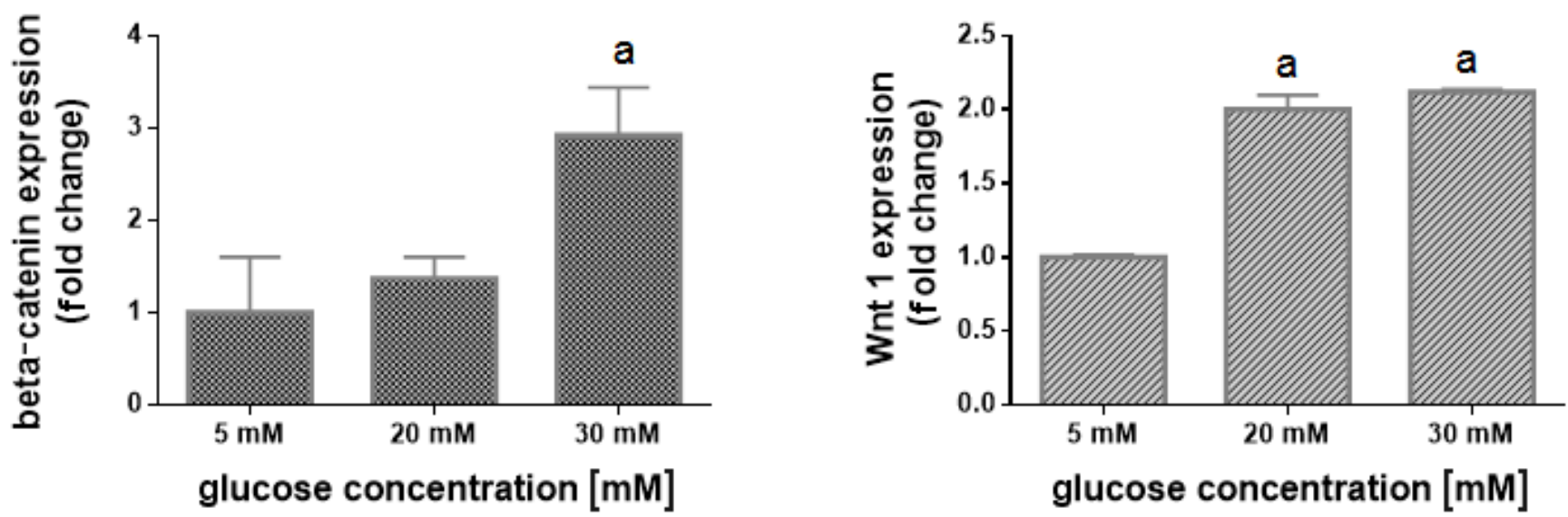

Fig. 4. Quantitative real-time polymerase chain reaction (qRT-PCR) analysis of gene expression of beta-catenin and Wnt-1 in the cells exposed to different concentrations of glucose

a significantly different from control $(p<0.001)$. The experiment was performed 3 times, each in triplicate.

Data presented as $M \pm S D$.
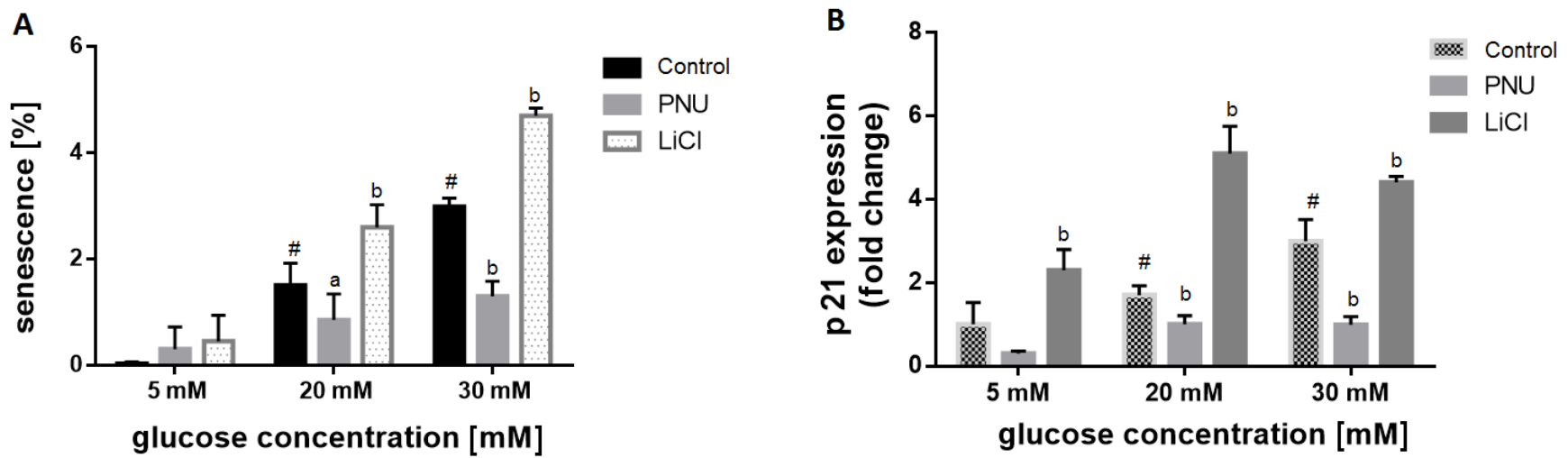

Fig. 5. Beta-galactosidase staining analysis and quantitative real-time polymerase chain reaction (qRT-PCR) analysis of p21 expression after exposing the cells to beta-catenin inhibitor (PNU-74654) and beta-catenin inducer (LiCl) at different glucose concentrations

A - percentage of the senescent cells after exposure to beta-catenin inducer or inhibitor at different glucose concentrations; B - expression of p21 in the cells after exposure to beta-catenin inducer or inhibitor at different glucose concentrations;

a significantly different from control on a specific day $(p<0.05)$; ${ }^{b}$ significantly different from control on a specific day $(p<0.001)$;

\# significantly different from control on day $7(p<0.001)$.

Data presented as $M \pm S D$.

\section{Discussion}

Senescence or cellular aging is a process that irreversibly ceases the proliferation of normal cells in response to external environmental factors or internal stimuli, such as telomere length shortening and oncogene induction. While maintaining their metabolic activity, the senescent cells undergo phenotypic changes in their structure and secretory profile. In this study, we attempted to investigate the influence of high glucose on cells isolated from pulp tissue in an in vitro model resembling the hyperglycemic condition in diabetic patients.

Considering that the fasting blood glucose of diabetic patients rises above $10 \mathrm{mM}$, in the present study - in order to simulate the diabetic state - the concentrations of $20 \mathrm{mM}$ and $30 \mathrm{mM}$ were used, in accordance with the concentrations applied in previous studies. ${ }^{18-20}$ The optimum concentration of $5 \mathrm{mM}$ in the cell culture medium was selected as the control group. Our results showed that the culture medium enriched with glucose could pose an inhibitory effect on the proliferation rate after 2 and 3 weeks of exposure, indicating the chronic influence of the hyperglycemic medium.

The beta-galactosidase staining method is regarded as the key test for the evaluation of cellular aging based on the level of lysosomal beta-galactosidase activity at $\mathrm{pH} 6$. While the optimum activity of the enzyme is at $\mathrm{pH} 4$, only the senescent cells with strong enzyme activity are detectable at $\mathrm{pH} 6 .{ }^{21}$ Our results showed that the number of beta-galactosidase-positive cells increased at the $20 \mathrm{mM}$ and $30 \mathrm{mM}$ glucose concentrations as compared to the control group. Along with beta-galactosidase activity, the expression of cyclin-dependent kinase (CDK) inhibitor p21 - the marker of cellular senescence - was increased. The data further confirmed the induction of senescence and cell cycle arrest during long-time exposure to the hyperglycemic condition. 
Human pulp tissue has a key role in the maintenance and repair of the teeth. It is comprised of the stromal cell population with a high capacity of differentiation into odontoblasts - the main functional cells in dentin regeneration. ${ }^{22}$ Previous studies in animal models have shown the association between diabetes and reduced pulp healing capacity. ${ }^{11}$ Also, few studies are available on bone marrow-derived stem cells, and the adverse effect of hyperglycemia on their proliferation and differentiation. ${ }^{23,24}$ Similarly to our results, Oancea et al. ${ }^{25}$ and Yan et al. ${ }^{26}$ also revealed the disturbance of dental pulp cell proliferation at high glucose. Recent research indicates that the exposure of bone marrow-derived hematopoietic stem cells to a high glucose-containing medium induces aging, genetic instability and telomere length changes in these cells. ${ }^{27}$ However, the precise mechanism of aging induction in these cells remains unclear. There is also further evidence on glucose-induced bone marrow-derived stem cell senescence and the causative role of oxidative-mediated autophagy. ${ }^{20}$ While less has been reported on the senescence response in diabetic pulp tissue or cultured pulp cells, our results clearly showed the induction of cellular aging in the cultured pulp cells exposed to long-term hyperglycemic conditions.

Searching for the underlying molecular mechanism, we observed the stimulation of the expression of Wnt1 and beta-catenin. Thereby, it hinted the involvement of the Wnt signaling pathway in glucose-induced pulp cell senescence. Indeed, the Wnt/beta-catenin signaling pathway plays an important role in various cellular processes, such as proliferation, differentiation, migration, survival, apoptosis, and pluripotency. ${ }^{28,29}$ The Wnt signaling pathway comprises both the canonical-betacatenin dependent and the non-canonical-beta-catenin independent pathways, and it is believed that the canonical pathway plays a key role in dentinogenesis and dentin regeneration. ${ }^{28}$ In the presence of Wnt ligand and binding to specific cell membrane receptors, cytoplasmic beta-catenin protein is transferred to the nucleus and activates the transcription of many target genes. In the present study, we applied PNU-74564, the binder of beta-catenin, to inhibit the Wnt signaling pathway. ${ }^{30}$ Lithium chloride is also known for its role in stabilizing beta-catenin through the inhibition of glycogen synthase kinase 3 beta (GSK3 $\beta$ ) activity, and therefore the activation of canonical Wnt signaling. ${ }^{31}$ Our results demonstrated that in the presence of beta-catenin inhibitor, the percentage of the senescent cells was reduced, while $\mathrm{LiCl}$ significantly enhanced glucose-induced senescence. The data further confirmed the involvement of Wnt signaling, particularly beta-catenin, in the progression of diabeticinduced cellular aging. Regarding the association between Wnt signaling and senescence, Liu et al. through in vitro and in vivo studies revealed that the activation of canonical Wnt-signaling triggers senescence in primary mouse embryonic fibroblasts and epithelial cells. ${ }^{32}$
Another study on thymocytes showed that the transgenic expression of beta-catenin induces cell growth arrest, DNA damage and senescence. ${ }^{33}$ Also, bone marrowderived stem cells from systemic lupus erythematosus patients exhibited signs of senescence and showed high activity of beta-catenin. ${ }^{34}$ Although there are some other studies which indicate the role of beta-catenin in the induction of cell proliferation. ${ }^{35,36}$

Further detailed clinical studies are essential to assess the pulp tissue proliferation rate and the level of betacatenin in diabetic patients. Based on the current results, Wnt signaling might be the potential target for the inhibition of the senescence response in the hyperglycemic condition, suggesting the development of bioactive materials applied in pulp capping that would be specific for diabetic patients.

\section{Conclusions}

The results of the present study showed that the diabetic condition disturbed pulp cell proliferation and induced the senescence phenotype, which is mediated by betacatenin/Wnt signaling. Such changes might compromise the healing and regenerative capacity of diabetic pulp. Based on the results of the current study and previous research, it is suggested that differential approaches in endodontic treatment need to be considered for diabetic pulp. Knowledge on the molecular mechanism of diabeticinduced senescence and targeting the key regulatory protein will help us find new therapeutic approaches in endodontic treatment for diabetic patients.

\section{ORCID iDs}

Mona Asghari (i) https://orcid.org/0000-0003-0352-1920 Nikoo Nasoohi (i) https://orcid.org/0000-0002-3374-5282

Mahshid Hodjat (D) https://orcid.org/0000-0001-8335-3546

\section{References}

1. Maffi $P$, Secchi A. The burden of diabetes: Emerging data. Dev Ophthalmol. 2017;60:1-5. doi:10.1159/000459641

2. International Diabetes Federation. IDF Diabetes Atlas. $6^{\text {th }}$ ed. 2013. https://www.idf.org/component/attachments/attachments. html?id=813\&task=download. Accessed March 2, 2020.

3. Al-Maskari AY, Al-Maskari MY, Al-Sudairy S. Oral manifestations and complications of diabetes mellitus: A review. Sultan Qaboos Univ Med J. 2011;11(2):179-186.

4. Mauri-Obradors E, Estrugo-Devesa A, Jané-Salas E, Viñas M, LópezLópez J. Oral manifestations of diabetes mellitus. A systematic review. Med Oral Patol Oral Cir Bucal. 2017;22(5):e586-e594. doi:10.4317/medoral.21655

5. Preshaw PM, Alba AL, Herrera D, et al. Periodontitis and diabetes: A two-way relationship. Diabetologia. 2012;55(1):21-31. doi:10.1007/ s00125-011-2342-y

6. Bender IB, Bender AB. Diabetes mellitus and the dental pulp. J Endod. 2003;29(6):383-389. doi:10.1097/00004770-200306000-00001

7. Goldberg M. Pulp aging: Fibrosis and calcospherites. In: Goldberg M, ed. The Dental Pulp. Biology, Pathology, and Regenerative Therapies. Springer-Verlag Berlin and Heidelberg; 2014:113-121. doi:10.1007/978-3-642-55160-4_8 
8. Catanzaro O, Dziubecki D, Lauria LC, Ceron CM, Rodriguez RR. Diabetes and its effects on dental pulp. J Oral Sci. 2006;48(4):195-199. doi:10.2334/josnusd.48.195

9. Inagaki $Y$, Yoshida $\mathrm{K}$, Ohba $\mathrm{H}$, et al. High glucose levels increase osteopontin production and pathologic calcification in rat dental pulp tissues. J Endod. 2010;36(6):1014-1020. doi:10.1016/j.joen.2010.03.018

10. Leite MF, Ganzerla E, Marques MM, Nicolau J. Diabetes induces metabolic alterations in dental pulp. J Endod. 2008;34(10):1211-1214. doi:10.1016/j.joen.2008.07.010

11. Garber SE, Shabahang S, Escher AP, Torabinejad M. The effect of hyperglycemia on pulpal healing in rats. J Endod. 2008;35(1):60-62. doi:10.1016/j.joen.2008.09.010

12. Blazer S, Khankin E, Segev $Y$, et al. High glucose-induced replicative senescence: Point of no return and effect of telomerase. Biochem Biophys Res Commun. 2002;296(1):93-101. doi:10.1016/s0006-291x(02)00818-5

13. Kitada K, Nakano D, Ohsaki $H$, et al. Hyperglycemia causes cellular senescence via a SGLT2- and p21-dependent pathway in proximal tubules in the early stage of diabetic nephropathy. J Diabetes Complications. 2014;28(5):604-611. doi:10.1016/j.jdiacomp.2014.05.010

14. Baeeri M, Momtaz S, Navaei-Nigjeh M, et al. Molecular evidence on the protective effect of ellagic acid on phosalone-induced senescence in rat embryonic fibroblast cells. Food Chem Toxicol. 2017;100:8-23. doi:10.1016/j.fct.2016.12.008

15. Ahmad Akhoundi MS, Rokn A, Bagheri R, Momeni N, Hodjat M. Urokinase-plasminogen activator protects periodontal ligament fibroblast from oxidative induced-apoptosis and DNA damage. J Periodontal Res. 2018;53(5):861-869. doi:10.1111/jre.12576

16. Baghaei K, Hashemi SM, Tokhanbigli S, et al. Isolation, differentiation, and characterization of mesenchymal stem cells from human bone marrow. Gastroenterol Hepatol Bed Bench. 2017;10(3):208-213.

17. Hodjat $M$, Haller H, Dumler I, Kiyan Y. Urokinase receptor mediates doxorubicin-induced vascular smooth muscle cell senescence via proteasomal degradation of TRF2. J Vasc Res. 2013;50(2):109-123. doi:10.1159/000343000

18. Matsui-Hirai $\mathrm{H}$, Hayashi $\mathrm{T}$, Yamamoto $\mathrm{S}$, et al. Dose-dependent modulatory effects of insulin on glucose-induced endothelial senescence in vitro and in vivo: A relationship between telomeres and nitric oxide. J Pharmacol Exp Ther. 2011;337(3):591-599. doi:10.1124/jpet.110.177584

19. Sibbitt JW Jr., Mills RG, Bigler CF, Eaton RP, Griffey RH, Vander Jagt DL. Glucose inhibition of human fibroblast proliferation and response to growth factors is prevented by inhibitors of aldose reductase. Mech Ageing Dev. 1989;47(3):265-279. doi:10.1016/0047-6374(89)90038-9

20. Chang TC, Hsu MF, Wu KK. High glucose induces bone marrowderived mesenchymal stem cell senescence by upregulating autophagy. PloS One. 2015;10(5):e0126537. doi:10.1371/journal.pone.0126537

21. Debacq-Chainiaux F, Erusalimsky JD, Campisi J, Toussaint O. Protocols to detect senescence-associated beta-galactosidase (SA-betagal) activity, a biomarker of senescent cells in culture and in vivo. Nat Protoc. 2009;4(12):1798-1806. doi:10.1038/nprot.2009.191

22. Goldberg M. Pulp anatomy and characterization of pulp cells. In: Goldberg M, ed. The Dental Pulp. Biology, Pathology, and Regenerative Therapies. Springer-Verlag Berlin and Heidelberg; 2014:13-33.doi:10.1007/978-3-642-55160-4_2

23. Stolzing A, Coleman N, Scutt A. Glucose-induced replicative senescence in mesenchymal stem cells. Rejuvenation Res. 2006;9(1):31-35. doi:10.1089/rej.2006.9.31

24. Zhang X, Meng K, Pu Y, Wang C, Chen Y, Wang L. Hyperglycemia altered the fate of cardiac stem cells to adipogenesis through inhibiting the $\beta$-catenin/TCF-4 pathway. Cell Physiol Biochem. 2018;49(6):2254-2263. doi:10.1159/000493828

25. Oancea R, Deak E, Popovici RA, Iliuta L, Sava-Rosianu R. Behavioural changes and plastic potential alteration of dental pulp stem cells exposed to high glucose concentrations. Dig J Nanomater Bios. 2013;8(1):313-321.

26. Yan L, Sun S, Qu L. Insulin-like growth factor-1 promotes the proliferation and odontoblastic differentiation of human dental pulp cells under high glucose conditions. Int J Mol Med. 2017;40(4):1253-1260. doi:10.3892/ijmm.2017.3117

27. Vinci MC, Vigorelli V, Raucci A, Genovese S, Pompilio G. Hyperglycemia drives myeloid CD34+ stem cells differentiation towards proinflammatory and senescent monocyte subpopulations. Eur Heart J. 2019:40(Suppl 1):ehz748.0730. doi:10.1093/eurheartj/ehz748.0730
28. MacDonald BT, Tamai K, He X. Wnt/beta-catenin signaling: Components, mechanisms, and diseases. Dev Cell. 2009;17(1):9-26. doi:10.1016/j.devcel.2009.06.016

29. Miki T, Yasuda SY, Kahn M. Wnt/ $\beta$-catenin signaling in embryonic stem cell self-renewal and somatic cell reprogramming. Stem Cell Rev Rep. 2011;7(4):836-846. doi:10.1007/s12015-011-9275-1

30. Trosset JY, Dalvit C, Knapp S, et al. Inhibition of protein-protein interactions: The discovery of druglike $\beta$-catenin inhibitors by combining virtual and biophysical screening. Proteins. 2006;64(1):60-67. doi:10.1002/prot.20955

31. Hedgepeth CM, Conrad LJ, Zhang J, Huang HC, Lee VM, Klein PS. Activation of the Wnt signaling pathway: A molecular mechanism for lithium action. Dev Biol. 1997;185(1):82-91. doi:10.1006/dbio.1997.8552

32. Liu H, Fergusson MM, Castilho RM, et al. Augmented Wnt signaling in a mammalian model of accelerated aging. Science. 2007;317(5839):803-806. doi:10.1126/science.1143578

33. Xu M, Yu Q, Subrahmanyam R, Difilippantonio MJ, Ried T, Sen JM. Beta-catenin expression results in p53-independent DNA damage and oncogene-induced senescence in prelymphomagenic thymocytes in vivo. Mol Cell Biol. 2008;28(5):1713-1723. doi:10.1128/MCB.01360-07

34. Gu Z, Tan W, Feng G, et al. Wnt/ $\beta$-catenin signaling mediates the senescence of bone marrow-mesenchymal stem cells from systemic lupus erythematosus patients through the p53/p21 pathway. Mol Cell Biochem. 2014;387(1-2):27-37. doi:10.1007/s11010-013-1866-5

35. Masckauchán TNH, Shawber CJ, Funahashi Y, Li CM, Kitajewski J. Wnt/beta-catenin signaling induces proliferation, survival and interleukin-8 in human endothelial cells. Angiogenesis. 2005;8(1):43-51. doi:10.1007/s10456-005-5612-9

36. Yang CM, Ji S, Li Y, Fu LY, Jiang T, Meng FD. $\beta$-catenin promotes cell proliferation, migration, and invasion but induces apoptosis in renal cell carcinoma. Onco Targets Ther. 2017;10:711-724. doi:10.2147/OTT.S117933 